\section{ReLIANT: Reader's guide to the Literature on Interventions Addressing the Need for education and Training}

\author{
Denise Koufogiannakis, \\ Andrew Booth \& \\ Alison Brettle
}

\begin{abstract}
Authors
Denise Koufogiannakis, Collections and Acquisitions Coordinator, University of Alberta Libraries, has completed a systematic review of methods for teaching information literacy skills to undergraduate students.
\end{abstract}

\begin{abstract}
Andrew Booth, Reader in Evidence Based Information Practice at ScHARR, University of Sheffield, has research interests in critical appraisal and Evidence Based Library \& Information Practice.
\end{abstract}

\begin{abstract}
Alison Brettle, Research Fellow, University of Salford, is undertaking research in Evidence Based Library \& Information Practice with particular interests in evaluation of information skills training.
\end{abstract}

Email: denise.koufogiannakis@ualberta.ca

\begin{abstract}
Librarians need to be able to read critically published accounts of educational and training interventions (ETI) and to apply the results to their own practice. One mechanism for assisting library practitioners in doing this is the critical appraisal checklist. This article describes the process of developing such a checklist involving a literature review of existing frameworks and experience in appraising such studies for a systematic review of information literacy skills training. The ReLIANT instrument is offered as a first attempt to equip library practitioners with a tool for use when appraising published reports of educational and training interventions.
\end{abstract}

\section{Acknowledgement}

The authors would like to acknowledge the University of Alberta which made this international collaboration possible by awarding professional leave to the principal author.

\section{Introduction}

Librarians have been teachers for well over a century (Walter, 2005). What has changed, however, is a shift in emphasis from providing information to their users towards equipping them with the knowledge and skills to find the information for themselves. From early beginnings, where such training may have comprised a perfunctory library orientation tour for new users, libraries now typically invest much time and effort in promoting information literacy, providing an array of one-to-one and group training opportunities. Many librarians trace this shift to the advent of CD-ROM products for end-users. CD-ROMs offered lowcost access to databases and required that librarians, freed from the pressures of connect time, showed their users how best to exploit these systems. From here the added requirement to produce documentation and then selfinstructional materials was a natural development of the librarian's role (Tang, 1998). More recently unmediated access to the Internet requires that librarians adopt a more proactive role to ensure that users not only acquire systematic search methods but also that they learn to discriminate between good and poor quality sources.

Against such a backdrop, with emphasis shifting from merely doing to an imperative for doing well, librarians have paid relatively little attention to establishing the quality and effectiveness of their own training provision. Typically programmes of library training are adopted with little objective evaluation of why, or whether, they had been successful elsewhere or, indeed whether any lessons learnt are directly comparable to the environment in which they are being introduced (Brettle, 2003). Reasons for this "evaluation bypass" (Sharples et al, 1999) include pragmatic pressures, from institutions and users, to introduce training programmes, an overdependence on the "exit questionnaire" as the main instrument with which to gauge success and a lack of knowledge in conducting evaluations. Other reasons, to be addressed specifically by this article, include poor quality reporting of published evaluations of education and training interventions and a lack of skills in reading and interpreting such reports. 
Within healthcare the evidence based paradigm has sought to equip practitioners with the skills to read, understand and apply the results from published research to their own professional practice. Tools to facilitate this process have included reader's or user guide's to the literature, tailored to common and important types of question or study design, and accompanying aide-memoires or checklists to ensure a common and consistent approach to interpretation (Katrak et al, 2004). At the same time complementary efforts have concentrated on improving the quality of the documentation of research through such mechanisms as structured abstracts (Hartley, 2004) and standards for the reporting of particular study designs (CONSORT, nd). Such initiatives have been mirrored within a specific health library context through the development of purposespecific checklists for common types of library research (Clyde, 2005). So, for example, the Critical Skills Training in Appraisal for Librarians (CriSTAL) initiative has developed checklists for assessing an Information Needs Analysis/Information Audit and for appraising a Use Study (Booth \& Brice, 2003).

This study aims to develop an instrument to assist librarians in reading published accounts of evaluations of educational and training interventions (ETIs), making judgements of reliability and validity and applying the results to their own practice. In doing this the authors hope to identify elements critical to the reporting of future evaluations, thus assisting other researchers in providing useful descriptions of their studies and helping in the conduct of further reviews and syntheses. It also provides an exemplar for how lessons learned from the health, and specifically health information, domain can impact on the wider development of evidence based library and information practice.

\section{Methodology}

The authors used a method previously conceived to develop the CriSTAL critical appraisal checklists (Booth \& Brice, 2003). One investigator (DK) examined studies of information skills training as part of a systematic review being conducted during professional leave. Key qualitative and quantitative features were identified for each study to ensure a standardised approach to assessment. Categories for data extraction were tested on a subset of eight articles included in the systematic review. Based on this pre-test of categories, further elements were added and used for all 122 included studies. Quality assessment of these research studies facilitated generation of a list of necessary criteria to be included in a proposed checklist. The review process highlighted that many critical elements, such as numbers of participants in each study, were not reported. These appraisal criteria, which fall within four domains of study design, educational context, results and relevance, were then converted into potentially answerable questions. This approach, involving creation of a new prototype instrument was previously labelled a "revolutionary approach" (Booth \& Brice, 2003).

Meanwhile another investigator ( $\mathrm{ABO}$ ) reviewed existing critical appraisal checklists, specifically within the field of educational interventions, for their value in creating the proposed tool. This approach, involving synthesis from existing instruments was previously described as an "evolutionary approach" (Booth \& Brice, 2003). Literature searches were conducted of MEDLINE, EMBASE, the Cochrane Library, ERIC, British Education Index, LISA and the Science and Social Science Citation Indexes for instruments specifically used to evaluate educational or training interventions. Although 33 such instruments were identified (Table 1) the content and pedigree of an overwhelming majority of these were considered to adopt too theoretical a perspective of educational interventions for them to be practically useful within the context of information skills training. The features of these frameworks were tabulated and analysed and these are to be presented in a full systematic review to be published later this year. The emphasis of this paper, in contrast, is on the development of a practical instrument for use by library and information researchers and practitioners and on our initial experience of using the resultant instrument. 


\begin{tabular}{|c|c|}
\hline Authors (Date) & Title \\
\hline Abbasi \& Smith (1999) & Guidelines for evaluating papers on educational interventions (C) \\
\hline Anderson \& Kerr (1968) & Checklist for evaluating educational research (C) \\
\hline Anderson (1971) & Check-list for evaluating analytical/literary studies (C) \\
\hline Brigley et al (1997) & Continuing medical education: the question of evaluation $(\mathrm{F})$ \\
\hline Colliver \& Robbs (1999) & Evaluating the effectiveness of major educational interventions (F) \\
\hline Dark \& Holsman (2002) & $\begin{array}{l}\text { Development of an evaluation checklist for communicating about environmental } \\
\text { education }(\mathrm{C})\end{array}$ \\
\hline $\begin{array}{l}\text { Dauphinee \& Wood-Dauphinee } \\
(2004)\end{array}$ & The need for evidence in medical education $(\mathrm{F})$ \\
\hline Dixon (1978) & Evaluation criteria in studies of continuing education in the health professions $(\mathrm{F})$ : \\
\hline Drescher et al (2004) & Towards evidence-based practice in medical training $(\mathrm{F})$ \\
\hline Farquhar \& Krumboltz (1959) & A check list for evaluating experimental research in psychology and education (C) \\
\hline General Teaching Council (n.d.) & Research of the month critical appraisal framework (C) \\
\hline Green $(2001)$ & $\begin{array}{l}\text { Identifying, appraising, and implementing medical education curricula: A guide } \\
\text { for medical educators (F) }\end{array}$ \\
\hline Hall et al (1988) & Published educational research - an empirical study of its quality (F) \\
\hline Harden et al (1999) & BEME Guide No $1(\mathrm{~F})$ \\
\hline Harden (2004) & Ten questions to ask when planning a course or curriculum (C) \\
\hline Hutchinson (1999) & Evaluating and researching the effectiveness of educational interventions (F) \\
\hline Israel et al (1995) & Evaluation of health education programs (F) \\
\hline Jolly (2001) & Control and validity in medical educational research $(\mathrm{F})$ \\
\hline Kohr (1970) & An instrument for evaluating survey research $(\mathrm{C})$ \\
\hline Morrison (2003) & ABC of learning and teaching in medicine - Evaluation $(\mathrm{F})$ \\
\hline Morrison et al (1999) & $\begin{array}{l}\text { Evidence-based education: development of an instrument to critically appraise } \\
\text { reports of educational interventions (C) }\end{array}$ \\
\hline Onwuegbuzie \& Daniel (2003) & $\begin{array}{l}\text { Typology of analytical and interpretational errors in quantitative and qualitative } \\
\text { educational research }(\mathrm{F})\end{array}$ \\
\hline Prideaux \& Bligh (2002) & Research in medical education: asking the right questions (F) \\
\hline Stacy \& Spencer (2000) & Assessing the evidence in qualitative medical education research $(\mathrm{F})$ \\
\hline Strauss (1969) & Guidelines for analysis of research reports $(\mathrm{F})$ \\
\hline Suydam (1968) & An instrument for evaluating experimental educational research reports $(\mathrm{C})$ \\
\hline Tuckman (1990) & A proposal for improving the quality of published educational research $(\mathrm{F})$ \\
\hline University of Glasgow (nd) & Critical appraisal checklist for an article on an educational Intervention (C) \\
\hline $\begin{array}{l}\text { U.S. Department of Education } \\
(2003)\end{array}$ & $\begin{array}{l}\text { Identifying and implementing educational practices supported by rigorous } \\
\text { evidence: a user friendly guide. (C) }\end{array}$ \\
\hline Van Dalen (1958) & A research checklist in education $(\mathrm{C})$ \\
\hline Van Driel \& Keisers (1997) & $\begin{array}{l}\text { An instrument for reviewing the effectiveness of health education and health } \\
\text { promotion }(\mathrm{C})\end{array}$ \\
\hline Ward et al (1975) & Evaluation of published educational research - national survey $(\mathrm{F})$ \\
\hline Wolf (2004) & Methodological quality, evidence, and research in medical education (RIME) (F) \\
\hline
\end{tabular}

$\mathrm{F}=$ general Framework; $\mathrm{C}=$ specific Checklist

Table 1 - Existing Evaluation Frameworks for Quality of Educational Research 


\section{The ReLIANT instrument}

The ReLIANT instrument comprises four substantive sections; study design, educational context, results and relevance. This compares with the classic three-fold division used by the Critical Appraisal Skills Programme (CASP), among others - validity (i.e. study design), reliability (i.e. results) and applicability (relevance). The addition of the fourth element, educational context, requires a brief word of explanation. Physical agents, such as drugs or diagnostic tests, rely on the basic "sameness" of the human body in demonstrating effectiveness. In contrast, educational interventions are "social" and their effect may be mediated or moderated by the context in which they are introduced and, indeed, by the personal effects of the person introducing them.
Finally, the substitution of "relevance" for the dimension of applicability, though comparatively minor, reflects the fact that applicability is usually determined on the fairly objective criterion of similarity of the population being studied to the population to which the results will be applied. Relevance is a far less deterministic judgement, recognising that it is a professional call as to whether the results from one population can be applied to another, possibly different, population. Relevance is thus a pragmatic feature associated with the "best available" evidence rather than with pursuit of an "ideal" gold standard of applicability.

\section{Study design}

- Is the objective of the study clearly stated? Is the reason for the study apparent?

- Is the population described in detail? Is the number of study participants clearly stated? Is there a description of participants (gender, age, race, academic level, level of previous library experience, etc)? Is the loss of any of the participants explained? Are participants required to participate in the course, or is their participation voluntary?

- Are groups of participants that are receiving different educational interventions similar in their size and population characteristics? Other than the difference of the intervention, are the groups treated equally throughout the research process?

- What research method was used? Was the research methodology clearly stated? Is it appropriate for the question being asked? Does the method attempt to avoid bias via randomization, blinding, etc. when possible?

- When were the learning outcomes measured? Is this a study looking at short-term, intermediate, or long-term effects?

- Is the research instrument described in detail? What questions were asked? What level of learning is the study addressing? Was the research instrument validated?

II. Educational context

- In what type of learning environment does the instruction take place? (E.g. university, college, secondary school, public library, special library, hospital, etc.)

- What teaching method was used? Is there a clearly outlined philosophy or theoretical basis behind the instruction?

- What mode of delivery was used? (e.g. Lecture, web-based tutorial, hands-on in computer lab, videoconference, etc.)

- Is the instructional topic clearly described? What was taught?

- Are learning objectives stated?

- How much instructional contact time was involved?

- What learning outcomes were measured? (could be cognitive, affective, behavioral learning outcomes) 


\section{Results}

- Are the results of the study clearly explained?

- Do the results address the original research question?

- Are the data presented in a clear manner, giving true numbers?

- Were appropriate tests for statistical significance carried out and reported?

- Was the reported outcome positive or negative in respect to the intervention?

- Does the reported data support the author's conclusions?

- Are potential problems with the research design presented?

\section{Relevance}

- Is the study population similar to my own user/teaching population?

- What information literacy competencies does this study address? Are these learning needs the same as those of my students?

- Are the practice implications of this research reported?

- Can the results of this study be directly transferred to my own situation, or what aspects of this study can I use to inform my practice?

\section{Table 2 - The ReLIANT Instrument}

\section{Initial experience of using the ReLIANT Instrument}

The ReLIANT instrument was first piloted in a workshop on How to Conduct and Interpret Evaluations of Information Skills Training conducted by two of the authors (DK \& $\mathrm{ABr}$ ) at the $3^{\text {rd }}$ International Evidence Based Librarianship Conference in Brisbane, Australia in October 2005. In preparation for this workshop, $\mathrm{DK}$ and $\mathrm{ABr}$ used the instrument to independently appraise a research article that would be given to workshop participants. There was a high level of agreement between the two appraisals and the results were combined to provide a "model answer" which would be given to participants at the end of the session. A summary section was added to the instrument to allow readers to obtain a quick initial overview of the study. While time and other practical constraints precluded a formal evaluation it will be helpful to share initial observations and preliminary experiences of using the instrument with approximately 70 participants from a wide variety of library sectors.

Following a short presentation about methods of conducting evaluations of information skills training, participants were given 40 minutes to read a paper and critically appraise its study design using the first section of the ReLIANT instrument. Participants were arranged in groups of 5-8 and had no prior sight of the paper or the checklist before the workshop. After spending some time reading the paper, lively discussions ensued in most groups following the format of the questions in the checklist. DK and $\mathrm{ABr}$ were on hand to facilitate. Interestingly, no questions were received regarding clarity of the instrument and participants appeared to have no problems in answering the predefined questions. A feedback session at the end of the workshop produced a high degree of agreement with the previously produced model answer. At the end of the session several participants commented on how much they had enjoyed the session, found it useful and would be taking the instrument back to their workplace to share and use. These observations, suggest that the checklist is user friendly, clear, comprehensive and easy to use without prior knowledge or training. The length of the instrument is more suited to those wanting to carry out in-depth critical appraisals of papers. Indeed session participants only had time to complete the first section on study design. A summary section was added to help those reading the results of critical appraisals to obtain a quick overview. It is recognised that further research is required to develop an 
abbreviated version of this checklist that will focus on those factors that are most critical to the quality of a published evaluation and thus to provide a rapid filter for critical appraisal.

\section{Conclusion}

Education and training is one of the most important emerging domains of library and information practice. A recent content analysis of library literature found that research in this domain comprises about $12 \%$ of one year's published output (Koufogiannakis et al, 2004). However the same survey found that the majority of these studies were descriptive, with smaller numbers of programme evaluations and cross-sectional studies. For this research to be utilised effectively by library practitioners requires the development of tools to assist in the evaluation and appraisal of content. Such tools must be readily accessible to practitioners using criteria that require a minimal amount of technical knowledge of research design. The authors believe that use of the RELIANT checklist will serve to increase awareness among practitioners of the critical factors involved when evaluating the published research of others as well as assisting in the design of evaluations to be conducted within their own library setting. A further by-product is an instrument that may be used by those conducting systematic reviews of the literature to ensure the consistent application of a framework for evaluation. Brice and Carlșon (2004), in evaluating the evidence base for educational activities, identified an important deficit:

To date, little emphasis has been given... to critically appraising evidence from the educational knowledge base.

The RELIANT checklist as described and piloted above is offered as an early attempt to meet this need.

\section{References}

Abbasi, K. and Smith, R. (1999) Education Group on Guidelines on Evaluation. Guidelines for evaluating papers on educational interventions, BMJ 318, I265-I267.

Anderson, J. (197I) Check-list for evaluating analytical/literary studies, Educational Research 13(2), 159-160.

Anderson J, and Kerr, A.H. (1968) Checklist for evaluating educational research, Educational Research II(I), 74-75.

Booth, A. and Brice, A (2003) Clear-cut? Facilitating health librarians to use information research in practice, Health Libraries Review, 20(I), 45-52.

Brettle, A. (2003) Information skills training: a systematic review of the literature, Health Libraries Review 20 (Suppl I), 3-9.

Brice, A. and Carlson, C. (2004) The contribution of evidence based practice to educational activities. In Booth, A \& Brice, A (Eds.), Evidence-based practice: $a$ handbook for information professionals, London: Facet Publishing, 164-77.

Brigley, S., Littlejohns, P., Young, Y., and McEwen, J (1997) Continuing medical education: the question of evaluation, Medical Education; 31, 67-71.

Clyde, L.A. (2005) The basis for evidence-based practice: evaluating the research evidence. Library and Information Congress: 7I th IFLA General Conference and Council, "Libraries - A voyage of discovery" August 14th - 18th 2005, Oslo, Norway. Available at: http://www.ifla.org/IV/ifla7I/papers/050e-Clyde.pdf [28/12/2005]

Colliver, J.A. and Robbs, R.S. (1999) Evaluating the effectiveness of major educational interventions, Academic Medicine 74(8), 859-60.

CONSORT (nd) CONSORT initiatives, Available at: http://www.consortstatement.org/Initiatives/complements.htm [28/12/2005]

Critical Appraisal Skills Programme (CASP) (2005) Available at: http://www.phru.nhs.uk/casp/ critical_appraisal_tools.htm [28//2/2005]

Dark, M.J. and Holsman, R.H. (2002) Development of an evaluation checklist for communicating about environmental education, Applied Environmental Education and Communication:An International Journal I (3), |83-191. 
Dauphinee, W.D. and Wood-Dauphinee, S. (2004)The need for Evidence in Medical Education:The development of best evidence medical education as an opportunity to inform, guide, and sustain medical education research, Academic Medicine 79 (10), 925-930.

Dixon, J. (1978) Evaluation criteria in studies of continuing education in the health professions: $A$ critical review and a suggested strategy, Evaluation and the Health Professions I, 47-65.

Drescher, U., Warren, F. and Norton, K. (2004) Towards evidence-based practice in medical training: making evaluations more meaningful, Medical Education 38 (12), 1288-1294.

Farquhar,W.W. and Krumboltz, J.D. (1959) A check list for evaluating experimental research in psychology and education, Journal of Educational Research 52(9), 353-354

General Teaching Council 'Research of the month' critical appraisal framework, Available at: http:/www.gtce.org.uk/shared/contentlibs//26795/ 93128//03260/ROMappframe.pdf [28//2/2005]

Green, M.L. (200I) Identifying, appraising, and implementing medical education curricula: $A$ guide for medical educators, Annals of Internal Medicine I35(10), 889-896.

Hall, B.W., Ward, A.W. and Comer, C.B. (1988) Published educational research - an empirical study of its quality, Journal of Educational Research 81 (3), 182-189.

Harden, R.M., Grant, J., Buckley, G., Hart, I.R. (1999) BEME Guide No I, Best Evidence Medical Education, Medical Teacher 21,553-562.

Harden, R.M. (1986) Ten questions to ask when planning a course or curriculum, Medical Education 20,356-365.

Hartley, J. (2004). Current findings from research on structured abstracts, Journal of the Medical Library Association 92(3), 368-37I.

Hutchinson, L. (1999) Evaluating and researching the effectiveness of educational interventions, BMJ 318 , 1267-1269.

Israel, B.A., Cummings, K.M., Dignan, M.B., Heaney, C.A., Perales, D.P., Simons-Morton, B.G., and Zimmerman, M.A. (1995) Evaluation of health education programs: current assessment and future directions, Health Education Quarterly 22, 364-389.

Jolly, B. (200I) Control and validity in medical educational research, Medical Education 35(10), 920-921.
Katrak, P., Bialocerkowski, A.E., Massy-Westropp, N., Kumar, S. and Grimmer KA. (2004) A systematic review of the content of critical appraisal tools. BMC Med Res Methodol. 16(4):22

Kohr, R.L. (1970). An instrument for evaluating survey research, Journal of Educational Research 64 (2): 78-85.

Koufogiannakis D, Slater L, Crumley, E. (2004) A content analysis of librarianship research. Journal of Information Science 30(3): 227-239.

Morrison, J. (2003) ABC of learning and teaching in medicine - Evaluation, BMJ 326 (7385): 385-387.

Morrison, J.M., Sullivan, F., Murray, E., and Jolly, B. (1999) Evidence-based education: development of an instrument to critically appraise reports of educational interventions. Medical Education 33, 890-893.

Onwuegbuzie, A. J., and Daniel, L.G. (2003). Typology of analytical and interpretational errors in quantitative and qualitative educational research, Current Issues in Education [On-line], 6(2). Available at http://cie.ed.asu.edu/volume6/number2/ [28//2/2005]

Prideaux, D. and Bligh, J. (2002) Research in medical education: asking the right questions, Medical Education 36 (I2): II|4-|||5.

Sharples, L.D., Caine, N., Schofield, P.M., Shapiro, L.M., Dunning, J. and Wallwork, J. (1999) Randomised trials of new surgical procedures are necessary, Heart $8 \mathrm{I}(1)$, 100-I.

Stacy, R., and Spencer, J. (2000) Assessing the evidence in qualitative medical education research, Medical Education 34(7), 498-500.

Strauss, S. (1969) Guidelines for analysis of research reports, Journal of Educational Research 63(4), 165.

Suydam, M.N. (1968). An instrument for evaluating experimental educational research reports, Journal of Educational Research 6I (5), 200-203.

Tang, J (1998) The expanding roles of librarians for the new millennium, IAssist Quarterly 22 (I): 19-23.

Available at: http://assistdata.org/publications/iq/iq22/ iqvol22 I tang.pdf [28/ /2/2005]

Tuckman, B.W. (1990) A proposal for improving the quality of published educational research, Educational Researcher 19(9): 22-25.

University of Glasgow. Critical appraisal checklist for an article on an educational intervention. Available at: http:/www.gla.ac.uk/departments/generalpractice/educ ational.PDF [28//2/2005] 
U.S. Department of Education, Institute of Education Sciences, National Center for Education Evaluation and Regional Assistance. Identifying and Implementing Educational Practices Supported by Rigorous Evidence: $A$ User Friendly Guide. Source 26p. Dec 2003 Available at: http://www.ed.gov/rschstat/research/pubs/rigorousevid/ rigorousevid.pdf [28//2/2005]

Van Dalen, D.B. (1958) A research checklist in education, Educational Administration \& Supervision 44, |74-181.

van Driel,W.G. and Keijsers, J.F. (1997) An instrument for reviewing the effectiveness of health education and health promotion, Patient Education and Counselling $30(1), 7-17$.

Walter, S.L. (2005) The Librarian in the Academy: Exploring the Instructional Role of Librarians in Higher Education: a Dissertation Submitted in Partial Fulfillment of the Requirements for the Degree of Doctor of Philosophy. Washington State University, College of Education, August 2005. Available at: http://www.dissertations.wsu.edu/dissertations/summer 2005/s_walter_072105.pdf [28/I2/2005]

Ward, A.W., Hall, B.W., Schramm, C.F. (1975) Evaluation of published educational research - national survey, American Educational Research Journal 12 (2): 109-128.

Wolf, F.M. (2004) Methodological quality, evidence, and research in medical education (RIME) Academic Medicine 79(10 Suppl), S68-S69. 